\title{
Deliberation of Gaming Addiction to Physical Activity and Health: A Case Study in South Korea
}

Razif Sazali, Siti Shazwani Ahmad Suhaimi, Nur Shuhamin Nazuri, Mohamad Firdaus Ahmad \& Lee Jong-Young

To Link this Article: http://dx.doi.org/10.6007/IJARBSS/v11-i10/11104

DOI:10.6007/IJARBSS/v11-i10/11104

Received: 06 August 2021, Revised: 30 August 2021, Accepted: 19 September 2021

Published Online: 10 October 2021

In-Text Citation: (Sazali et al., 2021)

To Cite this Article: Sazali, R., Suhaimi, S. S. A., Nazuri, N. S., Ahmad, M. F., \& Jong-Young, L. (2021). Deliberation of Gaming Addiction to Physical Activity and Health: A Case Study in South Korea. International Journal of Academic Research in Business and Social Sciences, 11(10), $605-620$.

Copyright: (c) 2021 The Author(s)

Published by Human Resource Management Academic Research Society (www.hrmars.com)

This article is published under the Creative Commons Attribution (CC BY 4.0) license. Anyone may reproduce, distribute, translate and create derivative works of this article (for both commercial and non-commercial purposes), subject to full attribution to the original publication and authors. The full terms of this license may be seen

at: http://creativecommons.org/licences/by/4.0/legalcode

Vol. 11, No. 10, 2021, Pg. 605 - 620

Full Terms \& Conditions of access and use can be found at http://hrmars.com/index.php/pages/detail/publication-ethics 


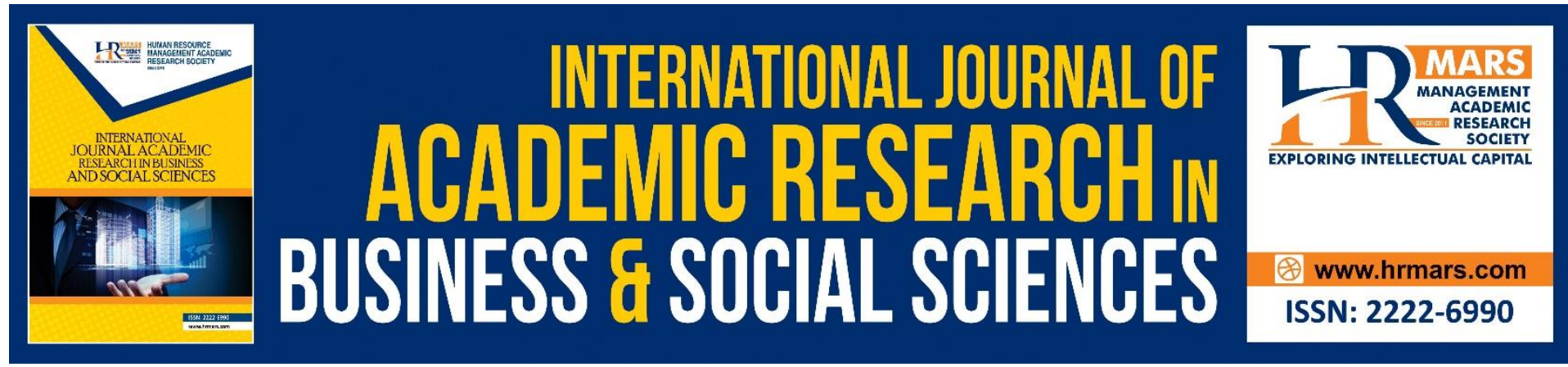

\title{
Deliberation of Gaming Addiction to Physical Activity and Health: A Case Study in South Korea
}

\author{
Razif Sazalia, Siti Shazwani Ahmad Suhaimi ${ }^{\mathrm{b}}$, Nur Shuhamin \\ Nazurib, Mohamad Firdaus Ahmad ${ }^{a} \&$ Lee Jong-Young ${ }^{c}$ \\ ${ }^{a}$ Faculty of Sports Science and Recreation, Universiti Teknologi MARA, Cawangan Negeri \\ Sembilan, Kampus Seremban, 'Department of Social and Development Sciences, Universiti \\ Putra Malaysia, Serdang, Malaysia Universiti Putra Malaysia, Serdang, Malaysia \\ 'The Academic Society of the South \& North Sports, South Korea \\ Email: razifsazali@gmail.com
}

\begin{abstract}
Every country is working on refining their latest technology to enables people to gain satisfaction in life. Playing games is considered one of the ways to socialize and meet around and create bonding. However, study in South Korea and China revealed that $24 \%$ of children in the respective country are diagnosed with heavy internet addiction especially in gaming. Hence, the current study attempted to determine the effect of virtual mobile and computer gaming on physical and health among undergraduate students at the University of Suwon (USW), South Korea. Through a quantitative survey among University of Suwon students, this study confirmed high level of daily routine activity, sleeping disorder, and anxiety. On the other hand, they also have moderate levels of depression and low level of social dysfunction. This study concluded that in general, the undergraduate students in Suwon University have moderate health level and the students are still facing the consequences of the effects of addiction due to heavy usage on mobile and computer gaming.
\end{abstract}

Keywords: Gaming Addiction, Depression, Anxiety, Sleeping Disorder, Physical Activity

\section{Introduction}

Computers and mobile devices are the new communication methods used in the current modern technology era. According to the United Nations Conference on Trade and Development UNCTAD (2019), analysing emerging digital economy trends has alluded to the increasing demand towards the evolution of Digital and information technology (IT) sectors as one of the main components. Therefore, every country is working on refining their latest technology which enables people to gain satisfaction in life in terms of computerized information, virtual type of games and marks their innovation of modern technology.

Generally, playing games is considered one of the ways to socialize and meet around and create bonding but nowadays, due to the enhancement of technological factors, it has evolved to multiple types of games such as virtual mobile and computer gaming (VMC) (Chen \& Leong, 2016). Also, venturing in VMC psycho socio-cultural perspective, based on the studies made in few countries in Asia has concluded on the motivation in playing VMC is 
because of the few factors such as ease to access, attractiveness, and being referred as a tool to seek distraction from unpleasant realities (Lopez-Fernandez et al., 2018). On the other hand, Omori and Felinto (2012) mentioned that people could quickly become addicted to a game because the gameplay process is easy. There are many factors that influence the individual to keep on playing the VMC, such as the influence of the friends or surrounding environment that motivates the gamers to keep playing and become addicted.

In addition, a study in South Korea and China revealed that $24 \%$ of children in the respective country are diagnosed with heavy internet addiction or known as IA, which needs the children to be hospitalized. In fact, more severe data regarding the addiction to computer gaming explains that since the year 2012 to 2013, there has been an increase in the statistical number of mobile users in China where it increased from 335 million users in 2012, but in 2013, it increased to 338 million. This figure clearly shows that addiction for mobile and computers is getting worse year by year, and serious action needs to be taken (Chi et al., 2019). Meanwhile, Erturkoglu et al. (2015) stated that the view of the method in mobile social games has changed to a mobile game business in generating income and profit-oriented. The user of VMC can purchase 'cheat tricks' or additional 'game equipment' to complete the challenges in the particular game.

Generally, addiction brings a broad knowledge of an area when it comes to determining the exact term of definition in addiction. It can be explained in various regions regarding a specific issue that is discussed and specializing in game addiction itself. The game is not harmful, but it can be caused by the activities that comply when playing the respective game and derives from the desire to win, which can cause the game's addiction. The term 'addiction' basically occurs by the inability of a person to control the behaviour, which causes the individual to lose control that can lead to harmful causes (West \& Hardy, 2006).

Meanwhile, Zeidan et al (2021) justified that addiction caused by problematic usage and affective temperaments refers to a particular behaviour as it arises from repetitive habits that enhance the potential risk and problems such as the person and social issues. This justification is another study also supported by Van Rooiji et al (2011), which indicated that addiction is a term that arises because the person is too attached to the game until they can't control themselves from playing, which subsequently leads to a certain level of harm to the individual.

On the other hand, with regards to the factors that can cause addiction on virtual game such as mobile and computer games, Areshtanab et al (2021), points out that the challenge and technical obstacle when the users engage when playing the game are the primary contributing factor on the addiction of the virtual game. Thus, the challenge and task faced by the player make the user gain excitement and cause the users to have the determination to solve the particular challenge. Eventually, this has created an addiction towards the users because the users will spend more time and keep on trying to overcome the challenge in order to win the game. On top of that, the players will also gain satisfaction and fun whenever they complete the mission or task that occurs in the challenge of the games. In short, past studies have indicated the effects of excessive hours of gameplay can inhibit the anger violation behaviour among the users. The gaming disorder due to addiction among the addictive users is also referred to as the DSM-IV or known as Diagnostic and Statistical Manual of Mental Disorders which are closely like drug addiction disorder (Smith, 2010).

There is also research done regarding the impacts of addiction in the academic area, but it focuses on the addiction on video game impacts. According to Zamani et al (2009), 
findings explain the cause of the addiction, emphasizing on students whose addiction to computer games experience effects on their physical and mental health in terms of mental disorder and social functioning disorder. Barbieri et al (2017) has reported that playing mobile games causes negative impacts as a series of cases and accidents occur. This situation happens when users (the person playing the game) concentrate on their games without concerning their safety and environmental traffic. The users seem to be in their own world and attached to the games until they cause injury to themselves and also towards the others around them. This clearly justifies the effects towards the users on their physical and health which they are addicted to the game. According to Docktormen (2013), there are cases where the users left their children abandoned at school, becoming too addicted until the users were unable to do other daily activities. The other effects of addiction to mobile and computer gaming also alter the behaviour of the users and their level of health where they started to neglect to practice a healthy lifestyle (Leung, 2002).

This study is vital because the gaming market in South Korea has been escalating over the years and being considered an ecosystem among the community. In regards to this, this has created a growing demand for VMC gaming, resulting in the changes of the non-normative behaviour (Rea, 2016). In fact, previously, Steward (2004) validated that $77 \%$ of school students are into VMC, which resulted in them experiencing difficulty in sleeping, time for physical socializing, and using the perks of online for educational purposes. In regards to that, this study will specifically look into any impact towards physical activity and health of these young generations of college students. However, to date, a lack of study has been conducted among Korean undergraduate students. Therefore, it is vital to study virtual mobile and computer gaming's effect on physical and health among physical and health undergraduate students at the University of Suwon (USW). In short, the general objective of this paper is to explore the effects of addiction with regard to virtual mobile and computer gaming that concentrate on physical and health among undergraduate students. The detailed objective is showed as below:

1. To identify the type of device preferred used by the students to video play games.

2. To illustrate the effects of daily routine activity, depression, sleep disorder, anxiety, and social dysfunction due to the addiction between the gender and years of study of the students.

3. To justify the level of addiction towards VMC among the undergraduate students of physical education college, University of Suwon

\section{Literature Review}

Nowadays, virtual mobile and computer gaming (VMC) has been played among adolescents including university students. According to Nahar et al. (2018) stated that on average in a day, students spend eight hours using technological equipment such as smartphones. Spending extended periods of time playing computer games may have negative long-term consequences that can lead to stress, restlessness, and physical tension (Alsheri \& Mohamed, 2019). Balakrishnan and Griffiths (2018) revealed that due to the addiction to the virtual game, individuals intend to forget to eat and spend hours playing their games and their daily routine has changed. Addiction towards VMC causes the involvement of physical activities to be affected and affects the health of the individual. Participation of individuals in physical activities is affected by many causes, the most seen causes being sex, age, and circumstances of economic, ethnicity, health, available time, life stage, playing games, and other responsibilities. 
Physical activity is found to decrease drastically through the period of adolescence, as suggested by numerous researchers since the turn of the century based on Caspersen et al (2000) and supported by Erwin (2008). Although numerous studies have been concerned about the importance of physical activity reported having relatively low PA levels among universities and colleges (Liu et al., 2018). There are a lot of programs held for the purpose of increasing the level of physical activity but $20 \%$ of adults remain physically inactive. Physical activity plays an important role towards maintaining and enhancing individual health. However, the participation in physical activity during leisure time remains low based on the acceptability of the student at university levels (Lotfi et al., 2011).

Generally, physical activity that influences health includes the capability of the body part to perform its function. According to Kurtus (2017), physical activity is another dimension of health that specifically states the situations that are free from any diseases or abnormality and the condition of well-being where the body can cooperate and perform its function. In order for the body to have good physical health, it needs enough nutrition intakes that enhance the productivity of the human immune system that prevent the person from falling sick. Without consuming less nutrition, the immune system may not be able to protect the body from getting infected with disease or in other words from getting sick. Nutrition also helps the body with the healing process of the body and enhances the body's work well. However, certainly, they are various type of game that can be chosen and game type such as sensor-based technology does enhance the body movement and create a variety of exercise based on the game structure but the positive effects on the health compared to a normal physical activity consumption is totally minor (Mellecker \& Mcmanus, 2013). In addition, the recommended amount of involvement in body exercising or physical activity is around 60 minutes of moderate physical activity daily. Yet, the users or gamers are more likely attracted to the game that makes them stay for a long time of hours as they don't need to move around to play the game because they intend to become lazier to perform any physical activity (Patry et al., 2013).

On the other hand, Zamani et al (2009) reveal that the addiction of VMC can cause an impact towards health. The World Health Organization defines health as a state of complete physical, mental, and social well-being and not merely the absence of disease or infirmity (Perugini, 2021). The users may experience effects in terms of their depression, sleep disorder, anxiety, and social dysfunction. Most of the effects are the negative effects that possibly occur towards the users and it happens when the users are addicted to certain types of virtual games.

Depression falls under psychopathological issues where the person ought to think they live in their own fantasy world. In Sharer (2012) study shows that there is a case reported when there is a boy in China that spends more than 5 hours daily playing a virtual game called Warcraft committed suicide when he failed to complete the mission in that respective game. The addiction to the virtual games is leading to a potential depression behaviour that engages among the users. Clearly, depression is harmful and if someone happens to have depression, they feel isolated from their own surroundings. Besides that, Akin and İskender (2011) mentions that the online game has causes negative results which lead to depression towards the users and the depression inhibits to another psychological issue as anxiety and stress level. Certainly, due to the factors, it created a social gap between the users and making the users to feel less happy. Therefore, to fulfil the social desire, the addicted users replace it with playing games. This case will ultimately affect the personal development of the users themselves and will make the level of depression become worse and higher. As the users 
become stressed or unhappy, they will engage into gaming because they think it would reduce their stress level and make them happier but it certainly is not.

Normal human body needs at least 8 hours of sleep a day. Lack of sleep may affect the performance of an individual's daily life whenever he or she is working or studying. Snyder (2003) suggests that males need more range of sleep with a minimum of 9 hours compared to females. In the study, it found that less sleep can bring other problems especially in terms of health problems which can cause hyperactive gag reflex, hyperactive deep tendon reflexes, and an increased sensitivity to pain. Thus, the study clearly states that lack of sleep can cause other health problems. In regards to individuality, the productivity of the person also will decrease when they get less sleep than their body needs.

According to Patry et al (2013), findings indicate that when a person becomes addicted to the virtual game the respective individual will have an increase in anxiety that derives due to the game difficulty. In fact, the individual will carry away the feelings in their real life and certainly will affect their life because the person will keep feeling uneasy when they are not capable of completing the certain mission of the virtual games. Next, Kipps et.al (2009) study explains that social dysfunction is the lack of social interaction among other human beings. It can be with friends, family members or anyone else. Basically, social dysfunction is where the person would likely spend most of the time with the things that they are into such as playing the virtual game rather than having a coffee session or socializing with their contacts. The impact of this negative behaviour will make the individual feel alone or unwanted and this can cause the person to become involved in other harmful activities such as becoming alcoholic and getting into drugs. On the other hand, Kipps et al (2009) illustrates that individuals that have social dysfunction difficulties may become more violence because they isolate themselves from society and that creates a border of the person with others.

\section{Methods}

The data for this paper was gathered using a random sampling method. A total of 169 respondents from undergraduate students of physical education college, University of Suwon were selected as the respondents. A self-administered method was employed in the data collection process. As most Koreans are unable to converse and understand the English language fully, the questionnaire has been translated to the Korean Language to ease the process. The questionnaire consists of three sections (Section A, B, and C) using the 5 points Likert scale as the response rate of the respondent.

Section $A$ is the socio-demographic respondents' section consisting of 5 items of respondent personal data: age, gender, current year of study, the device being used to play games, and total time spent daily playing video games. Section B is the physical activity of respondents consisting of 8 items that have been adopted from Recent Physical Activity Questionnaires (RPAQ) by Mindell et al (2009). Meanwhile, for Section C, health consists of four dimensions which are depression, sleep disorders, anxiety, and social dysfunction, adapted from General Health Questionnaires (GHQ-28) by (Nagyova et al., 2000).

Descriptive statistics such as frequency, percentage, mean, and standard deviation were used to fulfil the determined objective. Inferential analyses such as the independent ttest and ANOVA were used to determine any differences between socio-demographic and variables. Pearson correlation was used to determine whether there was a relationship between variables. Table 1 shows high reliability of instruments measures on Physical Activity and Health, where daily routine activity, depression, sleep disorder, anxiety, and social dysfunction demonstrated high values of Cronbach alpha ranging from 0.695 to 0.929 . These 
reveal that items employed in this study possess high internal consistency, where each set of items are closely related as a group.

Table 1: Reliability test

\begin{tabular}{lll}
\hline Variables & Cronbach & Alpha, \\
& $\alpha$ & \\
\hline Daily Routine Activity & .839 & \\
Depression & .695 & \\
Sleep Disorder & .929 & \\
Anxiety & .918 & \\
Social Dysfunction & .697 & \\
\hline
\end{tabular}

\section{Results \& Discussion}

\section{Demographic Information}

The demographic profile of the selected sample populations included age, gender, current year of study, the device being used to play games, and total time spent daily to play video games. The sample was spread out among all age groups: ages 21 and below had 46 respondents $(27.2 \%)$, ages between $22-24$ years had 95 respondents (53.8\%), and 28 respondents (18.9\%) were between 25-29 years old. Among these respondents, 116 (68.6\%) were male, and 53 (31.4\%) were female. Regarding the year of study, an almost equivalent number was represented in this research where Junior/ Senior Year recorded 89 (52.7\%), while Freshman/ Sophomore Year was 80 (47.3\%). Similarly, based on the device used to play games, 88 respondents (52.1\%) were into mobile, and 81 respondents $(47.9 \%)$ were into computer/ laptop/ pc games. Furthermore, the total time spent by the respondents to play the game are divided into two categories and the highest total of time spent by the respondents are less than 14 hours per week with a total of 118 respondents (69.8\%), while only 51 respondents (30.2\%) spent more than 14 hours per week.

Table 2: Socio-demographic profile

\begin{tabular}{lll}
\hline Variables & $\begin{array}{l}\text { Frequency } \\
\text { (n) }\end{array}$ & $\begin{array}{l}\text { Percentage } \\
\text { (\%) }\end{array}$ \\
\hline Age & 46 & 27.2 \\
21 and below & 95 & 53.8 \\
22-24 years old & 28 & 18.9 \\
25-29 years old & & \\
Gender & 116 & 68.6 \\
Male & 53 & 31.4 \\
Female & & \\
Current year of study & 80 & 47.3 \\
Freshman/ Sophomore Year & 89 & 52.7 \\
Junior/ Senior Year & & \\
Device being used to play games & 88 & 52.1 \\
Mobile & 81 & 47.9 \\
Computer/Laptop/PC & & \\
Total time spent daily playing video games & 118 & 69.8 \\
Less than 14 hours/ week & 51 & 30.2 \\
More than 14 hours/ week &
\end{tabular}


As portrayed in Table 3, it can be concluded that the majority of respondents have a high daily routine activity, sleeping disorder, and anxiety, whereby it accounted for $72.4 \%$, $54.4 \%$, and $81.7 \%$, respectively. The problem of sleeping disorders is due to the pressure of getting good grades in Korean culture. Therefore it resulted towards a high level of anxiety in this particular group of study. Meanwhile, it was found that most of the respondents had moderate levels of depression (56.8\%). Surprisingly, $55.6 \%$ of respondents have a low level of social dysfunction.

Table 3: Level of variables

\begin{tabular}{lllll}
\hline Variables & $\begin{array}{l}\text { Frequency } \\
\text { (n) }\end{array}$ & $\begin{array}{l}\text { Percentage } \\
\text { (\%) }\end{array}$ & Mean & SD \\
\hline Daily Routine Activity & 4 & 2.4 & & \\
Low & 41 & 24.3 & 4.041 & 0.755 \\
Moderate & 124 & 73.4 & & \\
High & & & & \\
Depression & 55 & 32.5 & & \\
Low & 96 & 56.8 & 2.719 & 0.741 \\
Moderate & 18 & 10.7 & & \\
High & & & & \\
Sleep Disorder & 9 & 5.3 & & \\
Low & 68 & 40.2 & 3.590 & 0.675 \\
Moderate & 92 & 54.4 & & \\
High & & & & \\
Anxiety & 3 & 1.8 & & \\
Low & 28 & 16.6 & 4.420 & 0.789 \\
Moderate & 138 & 81.7 & & \\
High & & & & \\
Social Dysfunction & 94 & 55.6 & & \\
Low & 71 & 42.0 & 2.546 & 0.3845 \\
Moderate & 4 & 2.4 & & \\
High & & &
\end{tabular}

Does gender bring any influence on these five factors (daily routine activity, depression, sleep disorder, anxiety, and social dysfunction) among Korean students at University of Suwon. Table 4 has provided the answers to this question. An independent ttest was conducted to know any differences. Based on the independent t-test performed, it can be concluded that females scored significantly higher $(p<0.05)$ than males in terms of daily routine activity, sleeping disorder, and anxiety. However, the differences between males and females were larger for anxiety (i.e., 0.367 ) compared to daily routine activity (i.e., 0.280 ) and anxiety (i.e., 0.283). These imply that females are more anxious compared to males due to psychological factors. These findings are consistent with some previous researchers (Olff et al., 2007; Verma et al., 2011; Rainville and Hodes, 2019) who claimed that gender differences explained psychological differences and biological stress reactivity. For example, women show more biological stress reactivity than men. Men may rise to believe more in their personal control over the situation, a variable protective against anxiety disorders compared to women. 
Table 4: Comparison of daily routine activity, depression, sleep disorder, anxiety and social dysfunction between gender groups through Independent sample t-test

\begin{tabular}{llllll}
\hline Variables & Gender & $\mathbf{n}$ & Mean & t value & $\mathbf{p}$ \\
\hline \multirow{2}{*}{ Daily Routine Activity } & Male & 116 & 3.953 & -2.271 & \multirow{2}{*}{0.024} \\
& Female & 53 & 4.233 & & \\
Depression & Male & 116 & 2.772 & 1.371 & 0.173 \\
\multirow{2}{*}{ Sleep Disorder } & Female & 53 & 2.604 & & \\
\multirow{2}{*}{ Anxiety } & Male & 116 & 3.498 & -2.570 & 0.011 \\
\multirow{2}{*}{ Social Dysfunction } & Female & 53 & 3.781 & & \\
& Male & 116 & 4.305 & -2.861 & 0.005 \\
& Female & 53 & 4.672 & & \multirow{2}{*}{0.203} \\
\hline
\end{tabular}

Mean scores are based on the Likert scale $1-5$, where 5 is the highest.

Significant at the 0.05 level (2-tailed).

Results presented in Table 5 indicated that only years of study have significant differences with sleeping disorders $(p=0.031)$. As we can see from the results, Freshman/ Sophomore year tends to have higher sleep disorders compared to Junior/Senior Year. This is because Freshman/Sophomore Year students attempt to balance out their life as new students and probably adapt to the university lifestyle (Gonta and Bulgac, 2019; Voronova et al., 2020). The first two years are also known as the most stressful years as they want to achieve a high Grade Point Average (GPA).

Table 5: Comparison of daily routine activity, depression, sleep disorder, anxiety, and social dysfunction between years of study groups through Independent sample t-test

\begin{tabular}{|c|c|c|c|c|c|}
\hline Variables & Year of study & $\mathbf{n}$ & Mean & $t$ value & $p$ \\
\hline Routine & Freshman/ Sophomore Year & 80 & 4.067 & \multirow{2}{*}{0.432} & \multirow{2}{*}{0.667} \\
\hline Activity & Junior/ Senior Year & 89 & 4.017 & & \\
\hline \multirow{2}{*}{ Depression } & Freshman/ Sophomore Year & 80 & 2.638 & \multirow{2}{*}{-1.383} & \multirow{2}{*}{0.159} \\
\hline & Junior/ Senior Year & 89 & 2.793 & & \\
\hline \multirow{2}{*}{ Sleep Disorder } & Freshman/Sophomore Year & 80 & 3.705 & \multirow{2}{*}{0.167} & \multirow{2}{*}{0.031} \\
\hline & Junior/ Senior Year & 89 & 3.481 & & \\
\hline \multirow{2}{*}{ Anxiety } & Freshman/Sophomore Year & 80 & 4.510 & \multirow{2}{*}{1.408} & \multirow{2}{*}{0.161} \\
\hline & Junior/ Senior Year & 89 & 4.339 & & \\
\hline \multirow{2}{*}{ Social Dysfunction } & Freshman/ Sophomore Year & 80 & 2.521 & \multirow{2}{*}{-0.830} & \multirow{2}{*}{0.408} \\
\hline & Junior/ Senior Year & 89 & 2.569 & & \\
\hline
\end{tabular}

Mean scores are based on the Likert scale $1-5$, where 5 is the highest.

Furthermore, Table 6 demonstrated differences in daily routine activity, depression, sleep disorder, anxiety, and social dysfunction between total time spent (less than 14 hours/ week) and (more than 14 hours/ week) in VMC. Respondents who spent more than 14 hours/weeks tend to have higher depression and social dysfunction than those who spent less than 14 hours/week. This is significant as students who spend more time in VMC intend to use that platform to escape from reality. Hence, having a lack of socializing skills resulted in high social dysfunction. Contradictory, the study showed that respondents who spent less than 14 hours/weeks have significantly higher daily routine activity, sleeping disorder, and 
anxiety than those who spent more than 14 hours/weeks. This indicates that the respondents who had spent less time on games have more physical activity with their peers. However, it could create anxiety when they aspire to compare their achievements, leading to sleeping disorders due to overthinking.

Table 6: Comparison of daily routine activity, depression, sleep disorder, anxiety and social dysfunction between total hours spend through Independent sample t-test

\begin{tabular}{|c|c|c|c|c|c|}
\hline Variables & Total time & $\mathbf{n}$ & Mean & t value & $\mathbf{p}$ \\
\hline \multirow{2}{*}{ Daily Routine Activity } & Less than 14 hours/ week & 118 & 4.256 & \multirow{2}{*}{5.584} & \multirow{2}{*}{0.000} \\
\hline & More than 14 hours/ week & 51 & 3.542 & & \\
\hline \multirow{2}{*}{ Depression } & Less than 14 hours/ week & 118 & 2.509 & \multirow{2}{*}{-5.487} & \multirow{2}{*}{0.000} \\
\hline & More than 14 hours/ week & 51 & 3.208 & & \\
\hline \multirow{2}{*}{ Sleep Disorder } & Less than 14 hours/ week & 118 & 3.764 & \multirow{2}{*}{4.725} & \multirow{2}{*}{0.000} \\
\hline & More than 14 hours/ week & 51 & 3.177 & & \\
\hline \multirow{2}{*}{ Anxiety } & Less than 14 hours/ week & 118 & 4.571 & \multirow{2}{*}{3.946} & \multirow{2}{*}{0.000} \\
\hline & More than 14 hours/ week & 51 & 4.071 & & \\
\hline \multirow{2}{*}{ Social Dysfunction } & Less than 14 hours/ week & 118 & 2.456 & \multirow{2}{*}{-4.080} & \multirow{2}{*}{0.000} \\
\hline & More than 14 hours/ week & 51 & 2.754 & & \\
\hline
\end{tabular}

Mean scores are based on the Likert scale $1-5$, where 5 is the highest.

Age differences have become a major thing in almost every issue, including social health and daily routine. Do younger people have better social health and daily routines or otherwise? Results presented in Table 7 inform us that there is a significant difference between age and depression, and sleeping disorder. This study has noticed some trends where the younger generation (less than 21 years old) scored higher on sleeping disorders than respondents aged 22-24 years old. Accordingly, sleep disorder occurs in a higher range for the age category below 21 years old as caused by adapting to new environments and adjusting period with the campus lifestyle compared to better adjustment seen in the age group of 22-24 years old. While for depression, Post Hoc Analysis indicated that those aged 22-24 years old have higher depression than respondents aged 25-29 years old due to the distribution of the workload in studying. 
Table 7: Comparison of daily routine activity, depression, sleep disorder, anxiety and social dysfunction between age groups through ANOVA analysis

\begin{tabular}{llllll}
\hline Variables & Age & $\mathbf{n}$ & Mean & $\mathbf{F}$ & $\mathbf{p}$ \\
\hline \multirow{3}{*}{ Daily Routine Activity } & $<21$ & 46 & 3.962 & & \\
& $22-24$ & 95 & 4.038 & 0.715 & 0.491 \\
& $25-29$ & 28 & 4.177 & & \\
Depression & $<21$ & 46 & 2.565 & & \\
& $22-24$ & 95 & 2.869 & 4.807 & 0.009 \\
Sleep Disorder & $25-29$ & 28 & 2.464 & & \\
& $<21$ & 46 & 3.752 & & \\
Anxiety & $22-24$ & 95 & 3.465 & 3.652 & 0.028 \\
& $25-29$ & 28 & 3.729 & & \\
Social Dysfunction & $<21$ & 46 & 4.539 & & \\
& $22-24$ & 95 & 4.345 & 1.028 & 0.360 \\
\multicolumn{7}{l}{ Mean scores are based on the Likert scale $1-5$, where 5 is the highest. } & \\
\hline
\end{tabular}

Finally, Table 6 presents Pearson correlations between routine activity, depression, sleep disorder, anxiety, and social dysfunction. Notably, the highest positive relationships are observed between daily routine activities and anxiety with $r=0.792$. The moderate positive correlations are observed between daily routine activities and sleeping disorder, daily routine activities and anxiety, depression and social dysfunction, with coefficients around 0.550 to 0.672. The moderate negative relationships are observed between social dysfunction and daily routine activities, sleeping disorder and depression, anxiety and depression, social dysfunction and sleeping disorder, social dysfunction and anxiety, with each has coefficient value around -0.548 to -0.634 . Meanwhile, the lowest negative relationship is observed between depression and daily routine activities with $r=-0.493$.

Table 8: Correlations between daily routine activity, depression, sleep disorder, anxiety and social dysfunction.

\begin{tabular}{llllll}
\hline & 1 & 2 & 3 & 4 & 5 \\
\hline 1. Daily routine activities & 1.000 & & & & \\
2. Depression & $-0.493^{* *}$ & 1.000 & & & \\
3. Sleep Disorder & $0.672^{* *}$ & $-0.634^{* *}$ & 1.000 & & \\
4. Anxiety & $0.633^{* *}$ & $-0.565^{* *}$ & $0.792^{* *}$ & 1.000 & \\
5. Social Dysfunction & $-0.548^{* *}$ & $0.550^{* *}$ & $-0.622^{* *}$ & $-0.609^{* *}$ & 1.000 \\
\hline
\end{tabular}

$* *$ Significant at the 0.01 level (2-tailed).

\section{Discussion and Conclusion}

Generally, based on this study's analysis, the students prefer to use the mobile device to play games, which is at $52.1 \%(n=88)$ compared to computer games with $47.9 \%(n=81)$. The factor may be that the students are not staying on the university campus, which needs them to commute daily to attend the class. Another factor is why the mobile device seems to be more convenient to carry. Moreover, this is also aligned with the statistics conducted by 
Statistica (2019), which mentioned that $65.7 \%$ of the population in South Korea are playing VMC, and 6 out of 10 Koreans played mobile games. Meanwhile, regarding the total time spent daily playing games, it has been found that 118 students mostly spend 14 hours or less $(69.8 \%)$ in a week, and 51 students $(30.2 \%)$ of them spending more than 14 hours per week playing VMC. Thus, according to Oskin (2012), a person can be defined as an early-stage addict if they spend more than at least 13 hours in a week ( 1.8 hours per day), equivalent to $30.2 \%$ from this group of study. In fact, this result also expanded on the National Information Society Agency (NIA) finding, which indicated that $8 \%$ from the age of 9 to 39 years of age are people suffering from online computer gaming addiction. However, VMC has become one of the tools to be used among people for socializing, and this is also proven by Foucault (2019) that acknowledge the Foucault theory of power and power relation where it explained gamers or the user considered the VMC as not just as one of the social hobby but by playing the games regularly, it alters the normal social behavior of them as they spend too much time for the respective game.

Respectively, although the level of addiction could be a concern that contributes towards moderate depression, the respondent showcased high consumption of physical activity, specifically in their daily routine activity. In this case, Mellecker and Mcmanus (2013) recommended spending at least 60 minutes on moderate physical activity in a day to maintain a healthy lifestyle. Physical activity may include walking, jogging, or any other activities that make the body produce sweat, which inhibits the heartbeat and makes the blood flow have better circulation. According to the depression perspective, Akin and İskender (2011), agreed that the online game has had a detrimental effect on individuals involved, resulting in depression, which hinders other psychological difficulties such as anxiety and stress levels. On the other hand, based on the analysis, the responding experiencing sleeping disorders and anxiety when they engaged into VMC. According to Ahmadi (1998), due to the addiction to the virtual game, the users intend to forget to eat and spend hours playing their games, and their daily routine has changed.

Moreover, according to Snyder (2003), the male needs more range of sleep with a minimum of 9 hours compared to the female. The study also found that less sleep can bring other problems, especially in terms of health problems, which can cause a hyperactive gag reflex, hyperactive deep tendon reflexes, and increased pain sensitivity. This is also compatible with Wang et al (2019) findings, which indicated that when a person becomes addicted to the virtual game, the individual will tend to increase anxiety derived from the game difficulty.

Positively, most of the respondents have not faced problems with socializing as they perceived the low dysfunction. Or else, if it is the vice versa, Kipps et al (2009) explained, individuals who have social dysfunction difficulties have a tendency to isolate themselves from society and that creates a border of the person with others and may become more violent. However, this can be solved as Bandura (1997) explains that humans can change their way of living if they find themselves involved in addiction through the belief of the individual and trusting their capability to make the changes to the situation they want to remove. The addiction of VMC can be improved or healed, but it depends on the affected individual's decision on how they want to make those changes.

Regarding the evaluation on the Korean law which is Article 12-3 (Actions for Preventing Excessive Game Immersion or Addiction) which explains that the game operator must limit their service to the public or they may be charged for penalty if they are founded disobey with the rules and regulation. The result is considered moderate, as they are slightly 
individual, especially the students who are still facing the consequences of the effects of addiction due to heavy usage on mobile and computer gaming.

This study aims to know the effects on physical activity and health experience due to the addiction to mobile and computer games. This research has a significant contribution to society and academic purpose, which: Firstly, this study will be helpful towards society. The outcome of this research revealed the truth behind the story of the consequences of excessive habits of playing games. Through this research, it was discovered that games could inevitably create addiction and able to develop negative impacts, especially on youth and children. Society needs to be aware of the psychological changes and health impacts of mobile and computer gaming addiction. Moreover, the result of the study can help to make changes to the individual that become addicted. Parents should exert control over their children if they appear overly attached since being too attached to games may negatively impact physical activity and health if played for an extended period of time.

Secondly, this study demonstrates that action can be taken to effect change rather than spend hours playing mobile or computer games. While it is evident that playing the game is pleasurable and entertaining, it can also result in addiction for individuals. Leisure time spent playing games can be restarted by engaging in healthy lifestyle activities such as socializing with friends and participating in various exercise types. Thus, rather than playing the game digitally, the individual can engage in other beneficial activities that will benefit his or her body's health and build a healthy lifestyle.

This research is essentially a continuation of past research efforts and is capable to serve as exploratory studies for the subsequent investigation. Hence, this study helps to explain the effects and prove the theory of addiction and also can be use for a tool to build up the knowledge. This indicates that this particular research can also be used to expand knowledge and ideas in the future. On top of that, it helps to clarify the understanding of information as it maintains the academic aspect of research needs. Therefore, the research can be continuously expanding as it can be explored in more depth depending on the trending game of mobile and computer.

\section{References}

Ahmadi, S. (1998). Social effects of computer games on male students in third year of guidance school in Isfahan city. Quarterly of public culture, 1, 87.

Akin, A., \& Iskender, M. (2011). Internet addiction and depression, anxiety and stress. International online journal of educational sciences, 3(1), 138-148.

Alshehri, A. G., \& Mohamed, A. M. A. S. (2019). The relationship between electronic gaming and health, social relationships, and physical activity among males in Saudi Arabia. American journal of men's health, 13(4), 1557988319873512..

Areshtanab, H. N., Fathollahpour, F., Bostanabad, M. A., Ebrahimi, H., Hosseinzadeh, M., \& Fooladi, M. M. (2021). Internet gaming disorder and its relationship with behavioral disorder and mother's parenting styles in primary school students according to gender in Iran. BMC psychology, 9(1), 1-7.

Balakrishnan, J., \& Griffiths, M. D. (2018). Loyalty towards online games, gaming addiction, and purchase intention towards online mobile in-game features. Computers in Human Behavior, 87, 238-246

Bandura, A (1977). Self-efficacy: Toward a unifying theory of psychological change. Psychological Review, 84,191-215. 
Barbieri, S., Vettore, G., Pietrantonio, V., Snenghi, R., Tredese, A., Bergamini, M., ... \& Feltracco, P. (2017). Pedestrian inattention blindness while playing Pokémon Go as an emerging health-risk behavior: a case report. Journal of medical internet research, 19(4), e86.

Caspersen, C. J., Pereira, M. A., \& Curran, K. M. (2000). Changes in physical activity patterns in the United States, by sex and cross-sectional age. Medicine \& Science in Sports \& Exercise, 32(9), 1601-1609.

Chen, C., \& Leung, L. (2016). Are you addicted to Candy Crush Saga? An exploratory study linking psychological factors to mobile social game addiction. Telematics and Informatics, 33(4), 1155-1166.

Chi, X., Liu, X., Guo, T., Wu, M., \& Chen, X. (2019). Internet addiction and depression in Chinese adolescents: a moderated mediation model. Frontiers in psychiatry, 10, 816.

Dockterman, E. (2013). The Science Behind the Candy Crush Addiction. Technology and Multimedia. https://business.time.com/2013/11/15/candy-crush-saga-the-sciencebehind-our- addiction/

Erturkoglu, Z., Zhang, J., \& Mao, E. (2015). Pressing the play button: What drives the intention to play social mobile games? International Journal of E-Business Research (IJEBR), 11(3), 54-71.

Erwin, H. E. (2008). Middle School Students' Leisure Activity Engagement: Implications for Park and Recreation Administrators. Journal of Park \& Recreation Administration, 26(3).

Foucault, M. (2019). Power: The essential works of Michel Foucault 1954-1984. Penguin UK.

Gonta, I., \& Bulgac, A. (2019). The Adaptation of Students to the Academic Environment in University. Romanian Journal for Multidimensional Education/Revista Romaneasca pentru Educatie Multidimensionala, 11(3).

Kipps, C. M., Nestor, P. J., Acosta-Cabronero, J., Arnold, R., \& Hodges, J. R. (2009). Understanding social dysfunction in the behavioural variant of frontotemporal dementia: the role of emotion and sarcasm processing. Brain, 132(3), 592-603.

Ron Kurtus (2017, Feb 13). What is Physical health. School for Champions. https://www.school-for-champions.com/health/what_is_health.htm\#.XVkk9-gzblX.

Leung, L. (2002). Loneliness, self-disclosure, and ICQ (" I seek you") use. CyberPsychology \& Behavior, 5(3), 241-251.

Liu, K. T., Kueh, Y. C., Arifin, W. N., Kim, Y., \& Kuan, G. (2018). Application of transtheoretical model on behavioral changes, and amount of physical activity among university's students. Frontiers in psychology, 9, 2402.

Lopez-Fernandez, O., Männikkö, N., Kääriäinen, M., Griffiths, M. D., \& Kuss, D. J. (2018). Mobile gaming and problematic smartphone use: A comparative study between Belgium and Finland. Journal of behavioral addictions, 7(1), 88-99.

Lotfi, M. H., Aminian, A. H., Ghomizadea, A., \& Lotfi, M. H. (2011). Leisure Times Status Amongst Students of Shahid Sadoughi University of Medical Sciences-Yazd, Iran. Int J Sports Manag Recretion Turism, 7, 44-52.

Mellecker, R. R., \& McManus, A. M. (2014). Active video games and physical activity recommendations: A comparison of the Gamercize Stepper, XBOX Kinect and XaviX JMat. Journal of Science and Medicine in Sport, 17(3), 288-292.

Mindell, J., Stamatakis, E., \& Brage, S. (2009). National Diet and Nutrition Survey Rolling Programme. Measuring physical activity in adults using the Recent Physical Activity Questionnaire (RPAQ). Retrieved from https://www.mrc-epid.cam.ac.uk/wp- 
content/uploads/2021/07/Measuring-PA-EE-in-NDNS-Comparison-Studyreport_FINAL.pdf

Nahar, N., Sangi, S., Rosli, N., \& Abdullah, A. H. (2018). Impak Negatif Teknologi Moden Dalam Kehidupan Dan Perkembangan Kanak-Kanak Hingga Usia Remaja (Negative Impact of Modern Technology to the Children'S Life and Their Development). UMRANInternational Journal of Islamic and Civilizational Studies, 5(1).

Nagyova, I., Krol, B., Szilasiova, A., Stewart, R., van Dijk, J., \& van den Heuvel, W. (2000). General Health Questionnaire-28: psychometric evaluation of the Slovak version. Studia Psychologica, 42(4), 351-362.

Olff, M., Langeland, W., Draijer, N., \& Gersons, B. P. (2007). Gender differences in posttraumatic stress disorder. Psychological bulletin, 133(2), 183.

Omori, M. T., \& Felinto, A. S. (2012). Analysis of motivational elements of social games: a puzzle match 3-games study case. International Journal of Computer Games Technology, 2012.

Oskin, B. (2012). Teens and video games: How much is too much. LiveScience. August, 10, 2012.

Patry, J. M., Burgess, C., LaPorte, T., \& Haber, M. G. (2013). Social anxiety, perceived real and virtual world social support, and problematic internet use among emerging adult massively multiplayer online role-playing game players. In Poster presentation at the 6th Conference on Emerging Adulthood, Chicago, IL.

Perugini, A. (2021). Mental Health Disparities in the United States are Unethical.

Rainville, J. R., \& Hodes, G. E. (2019). Inflaming sex differences in mood disorders. Neuropsychopharmacology, 44(1), 184-199.

Rea, S. C. (2017). Mobilizing games, disrupting culture: Digital gaming in South Korea. In Mobile gaming in Asia (pp. 73-89). Springer, Dordrecht.

Sharer, N. (2012). Examining social anxiety and depression among excessive online gamers (Doctoral dissertation, Marshal University, United States of America). Retrieved from https://mds.marshall.edu/cgi/viewcontent.cgi?referer=https://scholar.google.com/\&h ttpsredir $=1 \&$ article $=1264 \&$ context $=$ etd

Smith, C. B. (2010). Socio-spatial stigmatization and the contested space of addiction treatment: remapping strategies of opposition to the disorder of drugs. Social Science \& Medicine, 70(6), 859-866.

Snyder, S. L. (2003). The effects of sleep deprivation on individual productivity. (Degree dissertation). Available from ProQuest Dissertations \& Theses Global database (UMI Number: 1415597)

Statista. (2019). South Korea: gaming market size 2006-2022. Retrieved from https://www.statista.com/statistics/825058/south-korea-gaming-industry-size/.

Stewart, K. (2004). Informatization of a nation: A case study of South Korea's computer gaming and PC-bang culture (Doctoral dissertation, Communication, Art and Technology: School of Communication).

United Nations Conference on Trade and Development (UNCTAD). (2019). Digital Economy Report 2019: Value creation and capture: Implications for Developing Countries.

Van Rooij, A. J., Schoenmakers, T. M., Vermulst, A. A., Van Den Eijnden, R. J., \& Van De Mheen, D. (2011). Online video game addiction: identification of addicted adolescent gamers. addiction, 106(1), 205-212.

Verma, R., Balhara, Y. P. S., \& Gupta, C. S. (2011). Gender differences in stress response: Role of developmental and biological determinants. Industrial psychiatry journal, 20(1), 4. 
Voronova, L., Karpovich, I., Stroganova, O., \& Khlystenko, V. (2020). The Adapters public institute as a means of first-year students' pedagogical support during the period of adaptation to studying at a university. In Proceedings of the Conference "Integrating Engineering Education and Humanities for Global Intercultural Perspectives" (pp. 641651). Springer, Cham.

Wang, J. L., Sheng, J. R., \& Wang, H. Z. (2019). The association between mobile game addiction and depression, social anxiety, and loneliness. Frontiers in public health, 7, 247.

West, R., \& Hardy, A. (2005). Theory of addiction. New York, NY: Wiley-Blackwell.

Zamani, E., Chashmi, M., \& Hedayati, N. (2009). Effect of addiction to computer games on physical and mental health of female and male students of guidance school in city of Isfahan. Addiction \& health, 1(2), 98.

Zeidan, J., Hallit, S., Akel, M., Louragli, I., \& Obeid, S. (2021). Problematic smartphone use and affective temperaments among Lebanese young adults: scale validation and mediating role of self-esteem. BMC psychology, 9(1), 1-11. 